\title{
Ciências com sabor: uma experiência pedagógica de inovação e interdisciplinaridade
}

\author{
Sciences with flavos: a pedagogical experience of innovation and interdisciplinarity
}

\author{
Marli Duffles Donato Moreira ${ }^{1}$
}

\begin{abstract}
RESUMO: Este relato aborda a experiência do Projeto Ciências com Sabor desenvolvido no âmbito do Programa Institucional de Bolsas de Iniciação à Docência da Universidade Federal de Viçosa (PIBID/UFV). Este projeto foi desenvolvido na Escola Estadual Doutor Mariano da Rocha, localizada no Município de Teixeiras, MG, durante o ano letivo de 2019, com as turmas do Ensino Médio. A experiência pedagógica envolveu todos os pibidianos e professores supervisores juntamente com a coordenadora de área do núcleo Física-Matemática-Química do PIBID/UFV-Campus Viçosa registrando a participação de 296 alunos da escola. O trabalho contou com o apoio dos funcionários, professores e direção da escola. O projeto Ciências com Sabor teve como objetivo desenvolver o letramento científico dos estudantes, a partir de receitas culinárias, propondo um ensino para além da transmissão de conhecimentos (ensino tradicional), favorecendo a participação dos alunos, desenvolvendo autonomia e pensamento crítico. O trabalho desenvolveu-se numa perspectiva de pesquisa-ação de natureza qualitativa e fundamentou-se nos estudos de Leontiev (1978), Moreira (2016), Morin (2006), Cachapuz et al (2005) e Freire (2003). Os resultados apresentados apontam para a relevância e a conveniência de se considerar práticas pedagógicas interdisciplinares e contextualizadas no ensino de ciências na escola básica.
\end{abstract}

PALAVRAS-CHAVE: letramento científico; interdisciplinaridade; culinária.

\begin{abstract}
This report addresses the experience of the Sciences with Flavor Project developed under the Institutional Program for Teaching Initiation Scholarships at the Federal University of Viçosa (PIBID/UFV). This project was developed at the Doutor Mariano da Rocha State School, located in the Municipality of Teixeiras, MG, during 2019, with high school classes. The pedagogical experience involved all the pibidianos and supervisory teachers together with the area coordinator of the Physics-Mathematics-Chemistry nucleus of PIBID/UFV-Campus Viçosa, recording the participation of 296 students from the school. The work had the support of employees, teachers and school management. The Science with Flavor project aimed to develop students' scientific literacy, based on cooking recipes, proposing education beyond the transmission of knowledge (traditional teaching), favoring student participation, developing autonomy and critical thinking. The work was developed from a qualitative action research perspective and was based on studies by Leontiev (1978), Moreira (2016), Morin (2006), Cachapuz et al (2005) and Freire (2003). The results presented point to the

\footnotetext{
${ }^{1}$ Professora da Universidade Federal de Viçosa, Coordenadora do Núcleo Física-Matemática-Química PIBID/UFV-Campus Viçosa. ORCID 0000-0001-5653-5010 E-mail: marliddmoreira@ ufv.br Pibidianos: Adriano Costa da Silva; Amanda Cavalheiro Figueiras; Cláudio Henrique Soares Martins; Daniel Ramos Oliveira; Gecearia Rita Ramos Faria; Guilherme Serra Francisco Pinel; José Vitor Bicalho Diniz; Leonardo de Almeida Santos; Leonardo Silva Assunção; Letícia Pereira de Almeida; Lucas de Oliveira; Lucas Ribeiro Guimarães; Marcela de Oliveira Brahim Cortez; Marina Andressa Alves Pinheiro; Nicole Fernanda Caetano Morgado; Paloma de Paula Alves Coutinho; Paula Fernanda Ribas; Paulo Henrique Alves Anício; Sheila Gonçalves de Faria; Thaymara Cristina de Souza Rômulo; Thiago Araújo de Lima Matos; Wesley Clayton Primarte Aquino. Supervisores: Prof. Andre de Paula Homem; Prof. Ricardo Florencio Alves Rocha.
} 
relevance and convenience of considering interdisciplinary and contextualized pedagogical practices in science teaching in elementary school.

KEYWORDS: scientific literacy; interdisciplinarity; cooking.

\section{INTRODUÇÃO}

O processo de ensino-aprendizagem, na maioria das escolas brasileiras de educação básica, demanda por inovação, ou seja, introdução de novos modos de atuação docente, visto que as antigas práticas pedagógicas que exigem dos alunos apenas memorização de conteúdos e de fórmulas não estão gerando os resultados de aprendizagem esperados (MOREIRA, 2016). As aulas precisam motivar o aluno a questionar, a compreender, a assimilar e, principalmente, a conectar o seu conhecimento prévio ao construído em sala de aula para a compreensão dos problemas/fenômenos em seu cotidiano e na sociedade. É necessário, igualmente, desenvolver-se uma percepção da complexidade dos fenômenos a partir de uma abordagem interdisciplinar (MORIN, 2006). Dessa forma, a utilização de experiências simples do cotidiano para o Ensino de Ciências promove, com mais facilidade, o interesse e consequentemente a aprendizagem dos alunos, uma vez que essa abordagem ressalta a importância do estudo de fenômenos científicos (CACHAPUZ et al, 2005).

Diante disso, o projeto Ciências com Sabor fundamenta-se em Morin (2006), ao propor práticas de ensino que propiciem aos alunos experimentar, ver e pensar o conhecimento de uma forma complexa, integral e dinâmica. Quando falamos de complexidade, não empregamos o termo conforme o senso comum. Utilizamos a definição de Morin (2006) segundo a qual pensar a educação de forma complexa é perceber que ela é um processo formador do sujeito cidadão. Para isso, a autoformação deve estar atrelada à educação formal, de maneira a contribuir para a construção de um sujeito complexo que é atravessado pelas múltiplas dimensões nos âmbitos político, econômico, cultural, mitológico, religioso e ambiental, o que caracteriza uma biodiversidade dimensional. Entretanto, para a formação do sujeito complexo, faz-se necessária, aliás, indispensável, a apropriação de conceitos, concepções e ferramentas advindas dos processos de educação formal para que esses sujeitos se tornem aptos a captarem a substancialidade da vida em todas as dimensões supracitadas. Essa tarefa não é simples considerada a situação atual da educação brasileira a partir de fatores importantes como a fragmentação das áreas da ciência causada pela especialização desmedida e a restrição de saberes à parcela mais abastada da sociedade brasileira, fomentando desigualdades sociais, o descaso e a precarização da educação das classes populares configurando uma elitização das Ciências.

Nesse contexto, o projeto Ciências com Sabor teve como objetivo desenvolver o letramento científico dos estudantes, a partir de receitas culinárias, propondo um ensino para além da transmissão 
de conhecimentos (ensino tradicional), numa perspectiva inovadora e interdisciplinar, favorecendo a participação dos alunos, desenvolvendo autonomia e pensamento crítico, colocando em destaque as conexões entre os diferentes saberes. Utilizou-se da prática culinária, atividade que faz parte do cotidiano de todos os alunos, para observação e análise dos conceitos físicos/matemáticos/químicos envolvidos na elaboração das receitas.

De acordo com Paulo Freire (2003), a educação, qualquer que seja ela, é sempre uma teoria do conhecimento posta em prática. Nesse sentido, o Projeto Ciências com Sabor teve grande significado para os alunos, pois eles questionavam o método tradicional de ensino que não despertava seu interesse e manifestaram-se favoravelmente ao Ciências com Sabor afirmando que foi um ponto de partida para uma mudança no contexto de ensino/aprendizagem das ciências.

Além disso, os estudantes foram questionados no decorrer do projeto sobre diversos conceitos abordados, com o intuito de incentivar o pensamento científico e melhor compreensão da complexidade dos objetos em estudo.

\section{REVISÃO DA LITERATURA}

A Teoria da Atividade de Leontiev considera que o conhecimento é construído através do estabelecimento de relações entre o sujeito e os objetos que se encontram no seu meio, mediado socialmente. Leontiev (1978) sustenta que "o homem encontra na sociedade e no mundo transformado pelo processo sócio-histórico os meios, aptidões e saber-fazer necessários para realizar a atividade que mediatiza a sua ligação com a natureza" e, ainda, "o desenvolvimento do homem tem um caráter ecológico (quer dizer que depende das condições exteriores), mas não é um processo de adaptação em sentido próprio" (p. 185). Dessa forma, a construção do conhecimento é um processo interno, uma vez que depende das vivências anteriores para a assimilação dos conceitos, e externo, pois está pautada na interação do homem com o mundo. Ademais, depende também da realização de uma ação ou atividade sobre o objeto de estudo.

A atividade humana em sociedade gera cultura relacionada às ações de escrever, ler, falar e entender os fenômenos. Dessa forma, os conhecimentos científicos são objetos culturais. Segundo Moreira (2016, p.30), “os valores de uma determinada cultura funcionam como um elemento de coesão e de identificação social e é tema indispensável no cenário escolar”. Assim, a escola é o espaço onde se estabelecem as relações aluno-professor-conhecimento científico e, cabe a ela criar possibilidades de ensino-aprendizagem numa perspectiva problematizadora. 
A aprendizagem é, também, uma atividade individual e está diretamente relacionada à interação do aluno com o objeto de estudo mediada pelo professor. Desse modo, o processo de apropriação do conhecimento científico se dá de maneira individual, a depender das vivências de cada educando. Segundo Freire (2011), o método bancário é a transmissão de conhecimento educador/educando sem que ocorra interação entre eles. O protagonista não é o aluno. Em contraponto, a educação problematizadora é aquela que provoca a reflexão e a indagação pelo aluno a partir de interações e investigação.

A educação que se impõe aos que verdadeiramente se comprometem com a libertação não pode fundar-se numa compreensão dos homens como seres vazios a quem o mundo 'encha' de conteúdos; (...) Não pode ser a do depósito de conteúdos, mas a da problematização dos homens em suas relações com o mundo. (...) Quanto mais se problematizam os educandos, como seres no mundo e com o mundo, tanto mais se sentirão desafiados. Tão mais desafiados, quanto mais obrigados a responder ao desafio. Desafiados, compreendem o desafio na própria ação de captá-lo. Mas, precisamente porque captam o desafio como um problema em suas conexões com outros, num plano de totalidade e não como algo petrificado, a compreensão resultante tende a tornar-se crescentemente crítica, por isto, cada vez mais desalienada. (FREIRE, 2011, p. 77-80)

Nessa lógica, ao adentrarmos numa instituição de ensino, deparamo-nos com uma determinada cultura escolar. Podemos perceber que cada educador possui um modo de mediar o processo de aprendizagem, alguns pelo método bancário, outros pelo problematizador... Esse primeiro tem se tornado cada vez mais frequente entre os educadores, os quais preferem apenas transmitir o conteúdo sem gerar questionamentos pelos alunos. Assim, a aula torna-se uma narração, na qual o protagonista é o professor e os educandos, ouvintes, "recipientes" que comportam conhecimentos sem, por vezes, darem-se conta da importância e possibilidades de como aplicá-los. Em contrapartida, a problematização promove a liberdade de expressão do pensamento dentro da sala de aula, onde o protagonista passa a ser o aluno. Segundo Freire (2011), o papel do professor é instigar a investigação, reflexão e crítica do educando por meio de inquietações, tornando assim ambos sujeitos de aprendizagem, em que o aluno aprende e o educador reflete sobre a sua prática. É evidente a necessidade de uma transformação na maneira de pensar, ensinar e aprender na escola. Morin (2006) defende a valorização de um conhecimento não fragmentado que permita a homens e mulheres enxergarem o mundo de maneira contextualizada, abrangente e complexa.

Cachapuz et al (2005) defende esta necessária transformação no ensino das Ciências. Nessa lógica, faz-se necessária, e urgente, uma renovação no ensino das Ciências (diz-se aqui, 
especialmente, acerca da Física, Química e Matemática), de modo a inovar o ensino, as práticas docentes e a concepção dessas ciências.

Mas a aprendizagem das ciências pode e deve ser também uma aventura potenciadora do espírito crítico no sentido mais profundo: a aventura que supõe enfrentar problemas abertos, participar na tentativa de construção de soluções ... a aventura, em definitivo, de fazer ciência (CACHAPUZ, 2005, p.30).

A construção, manutenção e desenvolvimento de uma sociedade com valores de justiça social, ética, sustentabilidade e solidariedade implica a necessidade de compreensão dos conceitos científicos, de seus usos e implicações promovendo os indubitáveis contributos da alfabetização científica na vida dos cidadãos.

\section{METODOLOGIA: A EXPERIÊNCIA PEDAGÓGICA CIÊNCIAS COM SABOR}

Este trabalho desenvolveu-se numa perspectiva de pesquisa-ação de natureza qualitativa e fundamentou-se nos estudos de Leontiev (1978), Moreira (2016), Morin (2006), Cachapuz et al (2005) e Freire (2003). A pesquisa-ação é definida, segundo Thiollent (2011, p.14), como

[...] um tipo de pesquisa social com base empírica que é concebida e realizada em estreita associação com uma ação ou com a resolução de um problema coletivo e no qual os pesquisadores e os participantes representativos da situação ou do problema estão envolvidos do modo operativo ou participativo.

Desta forma, pesquisamos/discutimos práticas pedagógicas que envolvessem as disciplinas de Física, Matemática e Química. Construímos a proposta a partir da ideia de utilizar experiências presentes no cotidiano dos alunos da escola. Assim, pensamos na cozinha como espaço pedagógico e alternativo para o desenvolvimento da nossa proposta pedagógica.

Freire (2011) relata ser fundamental pensar que o educando e o educador estão inseridos em um contexto, fazendo e refazendo suas realidades, ao passo que são por elas transformados. Assim sendo, tratar a Ciência presente no dia a dia pode tornar a aprendizagem mais significativa para ambos. Seguindo os objetivos do projeto, utilizamos a culinária como ferramenta pedagógica. 
No primeiro momento, as discussões voltaram-se para a escolha das receitas que seriam mais adequadas para tal propósito. Durante a pesquisa, optou-se por desenvolver o trabalho em duas edições: Cupcake $^{2}$, na primeira etapa do projeto, e Gelatina, na segunda etapa (Figura 1).

Figura 1. Alunos nas duas edições do projeto Ciências com Sabor.

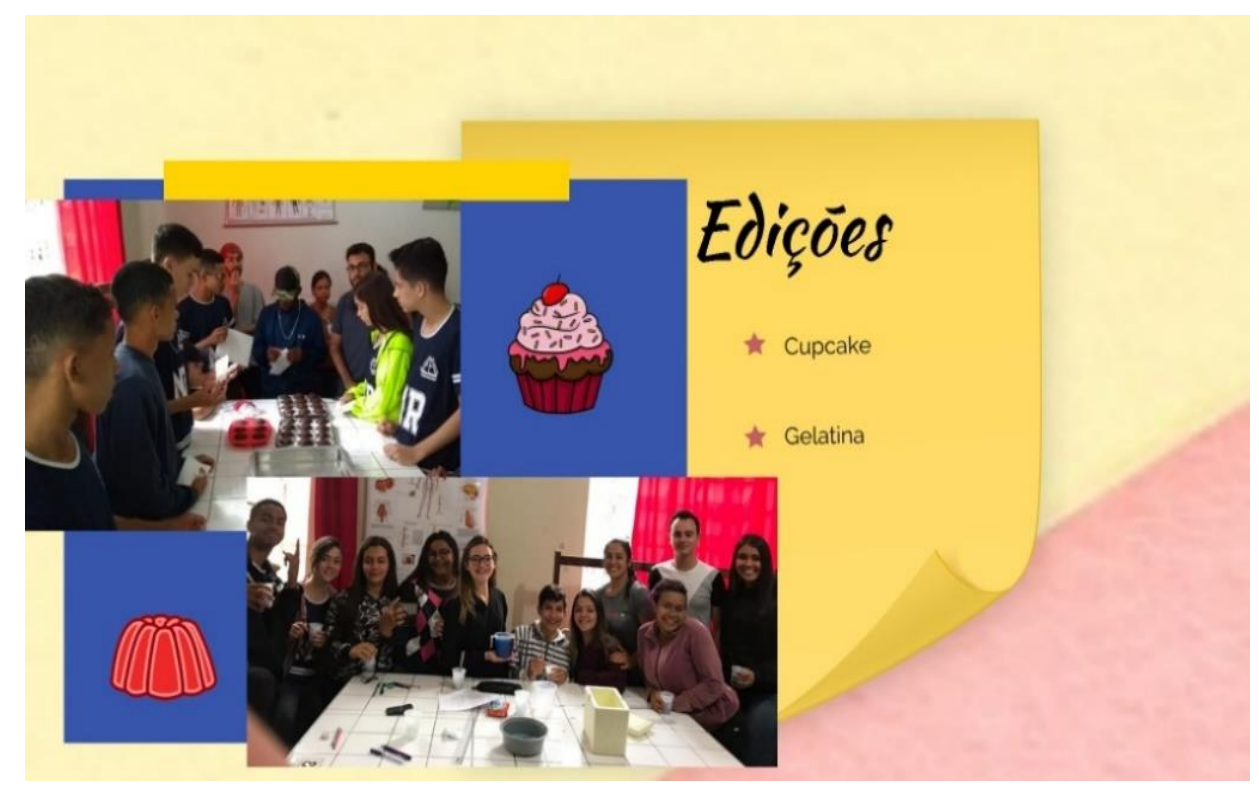

Fonte: Arquivo próprio

Após esse primeiro momento, os planos de aula foram preparados, constituídos de duas partes: teórica e prática. Listamos, em seguida, os conceitos científicos que seriam explorados nas respectivas receitas (medidas e unidades; processos de transferência de calor; escalas de temperatura; estados físicos da matéria; densidade; misturas e reações; porcentagem; frações; formas geométricas; etc). Feito isso, aplicamos um questionário inicial para os alunos de todas as turmas do Ensino Médio (9 turmas) a fim de diagnosticar os conhecimentos prévios acerca dos assuntos a serem abordados. Organizamos um calendário de trabalho separado com cada turma do Ensino Médio de tal forma que numa semana trabalharíamos a parte teórica - na Sala de Aula - e, na seguinte, a parte prática - no Laboratório de Ciências - (Figura 2).

\footnotetext{
${ }^{2}$ Pequeno bolo
} 
Figura 2. Aulas teóricas e práticas do projeto Ciências com Sabor.

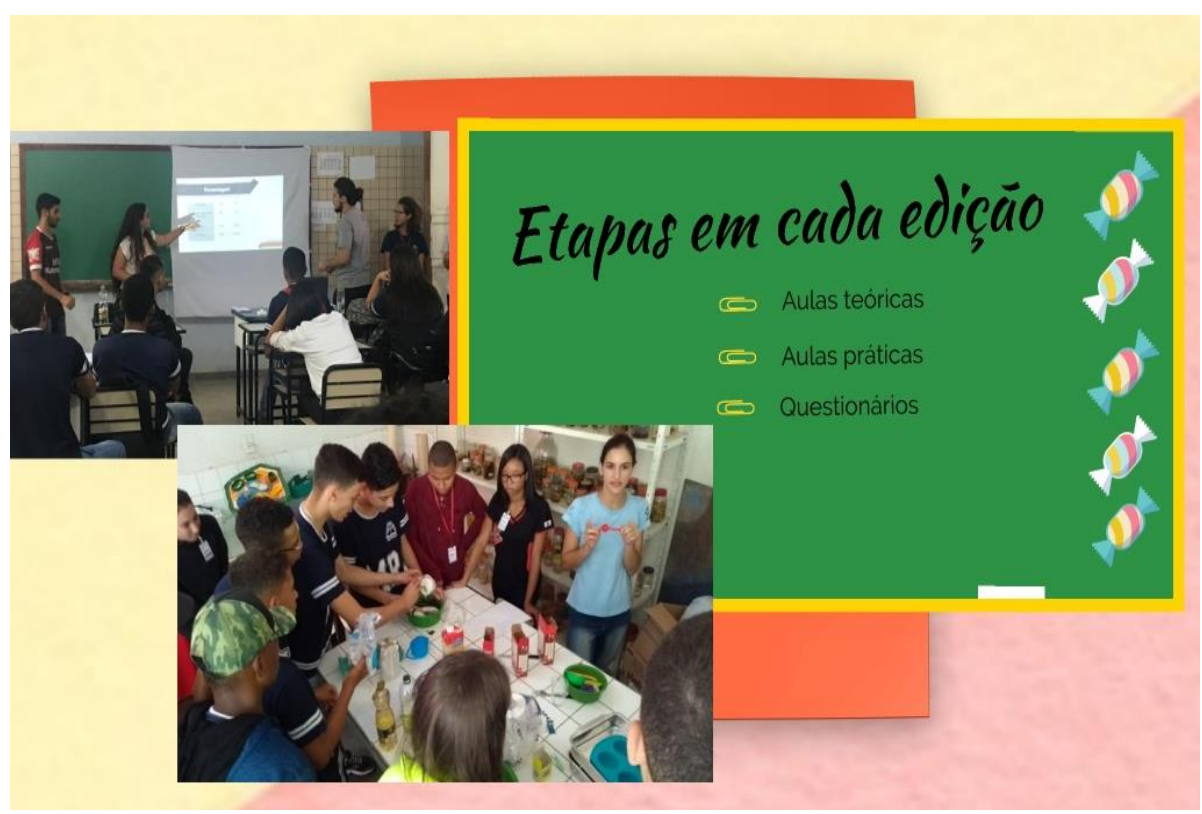

Fonte: Arquivo próprio

\section{DESENVOLVIMENTO DAS ETAPAS}

(i) Cupcake: A primeira aula foi teórica desenvolvida com suporte de apresentação gráfica pelo PowerPoint. Os pibidianos que lecionaram focaram no método investigativo, no qual os alunos são estimulados a participarem de forma ativa. Assim, levou-se um experimento que demonstrava a reação química similar da fermentação do cupcake.

Figura 3. Alunos no Laboratório de Ciências fazendo o cupcake.

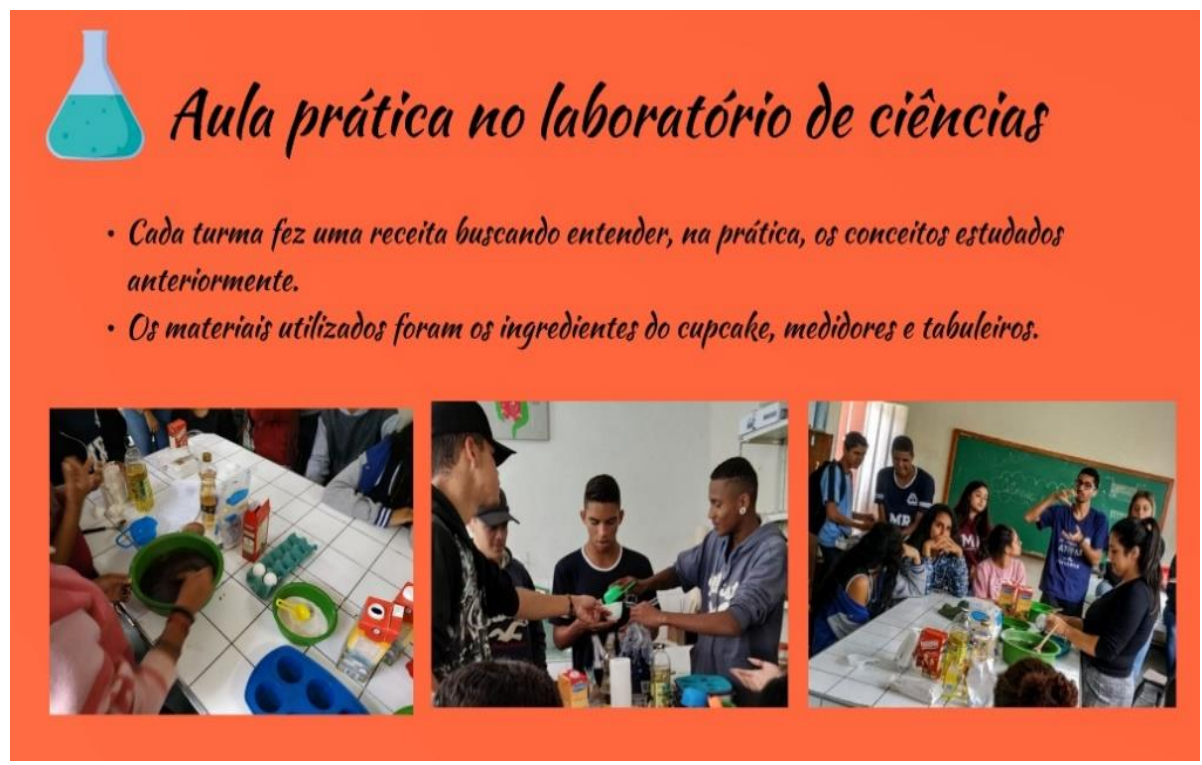

Fonte: Arquivo próprio 
A segunda aula foi prática (Figura 3) na qual os alunos puderam produzir o cupcake. Nesta etapa, pôde-se observar que os alunos já percebiam os processos constituintes da prática e especulavam pormenores científicos com os quais se defrontavam. Finalizado este momento, veio o mais aguardado pelos educandos: a degustação do cupcake.

(ii) Gelatina: Os objetivos gerais de abordar os processos físicos, químicos e matemáticos envolvidos na execução das receitas foram mantidos, entretanto optou-se por inverter a ordem das aulas.

Figura 4. Alunos no Laboratório de Ciências fazendo a gelatina.

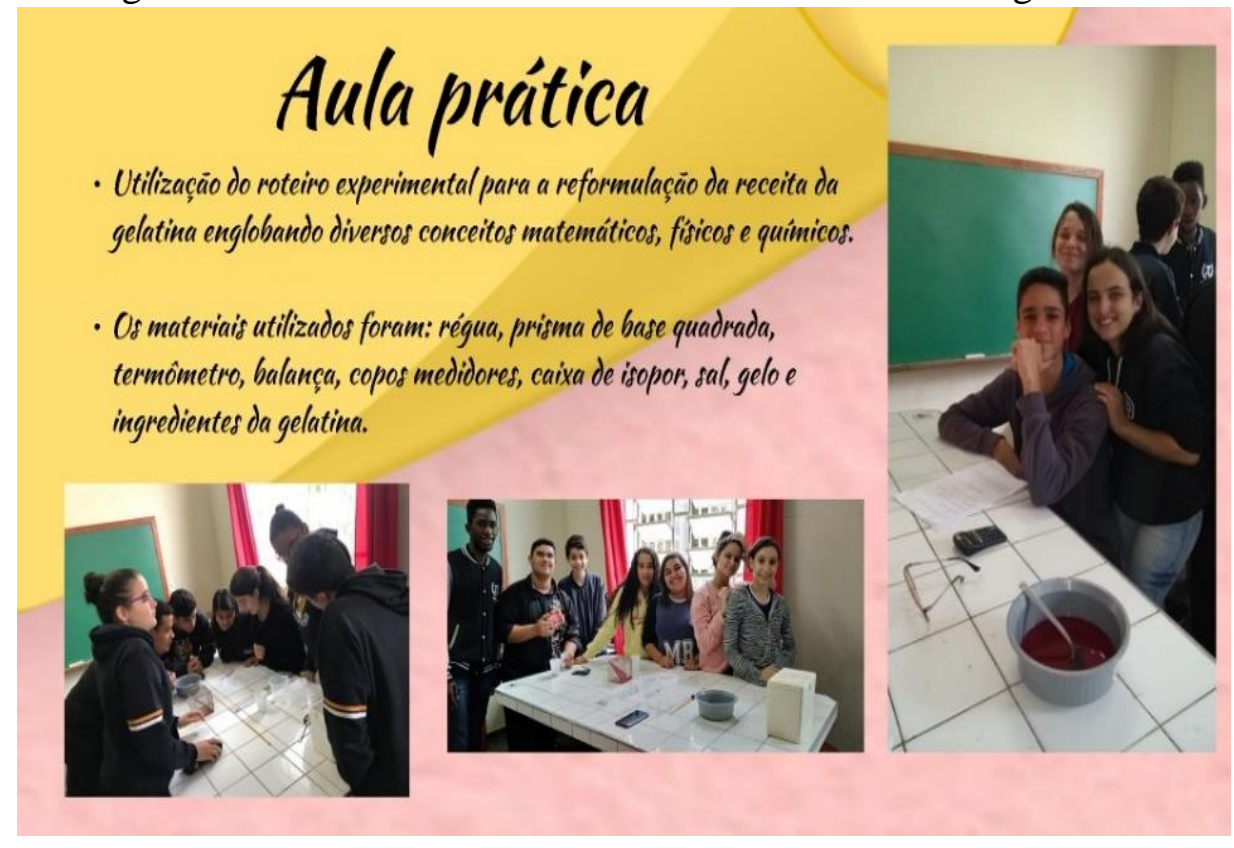

Fonte: Arquivo próprio

Inicialmente, ocorreu uma aula prática e os alunos receberam um roteiro experimental com o passo-a-passo sobre como fazer a gelatina e com perguntas que promoviam a reflexão sobre os diversos conceitos científicos presentes no experimento (Figura 4). A segunda aula foi teórica, na qual foram explicados/discutidos os conceitos anteriormente observados.

\section{RESULTADOS: A EXPERIÊNCIA PEDAGÓGICA CIÊNCIAS COM SABOR}

Para o primeiro momento, a análise dos resultados utilizou-se de questionários sobre os conteúdos abordados. Houve um primeiro questionário anterior à explicação teórica dos conceitos em sala de aula e um segundo, depois da prática experimentada. Após a conclusão dessa primeira 
parte do projeto, comparamos os questionários respondidos pelas diferentes turmas. Nosso intuito foi o de avaliar o conhecimento construído pelos alunos durante a realização do projeto.

\section{ETAPA 1: Cupcake de Chocolate}

Foi aplicado, inicialmente, um questionário com perguntas sobre as ideias que os alunos tinham sobre os conceitos abordados em sala de aula e para conhecer o que eles inferiam sobre a ciência presente na preparação do cupcake. Dessa forma, motivamos a participação dos alunos no projeto, despertando o interesse e a curiosidade. Para a análise dos questionários (abordagem qualitativa), fizemos nuvens de palavras com as respostas dos estudantes, destacando a compreensão dos alunos sobre os fenômenos científicos presentes na experiência (Figura 5).

Figura 5. Nuvens de palavras referentes ao Questionário 1.
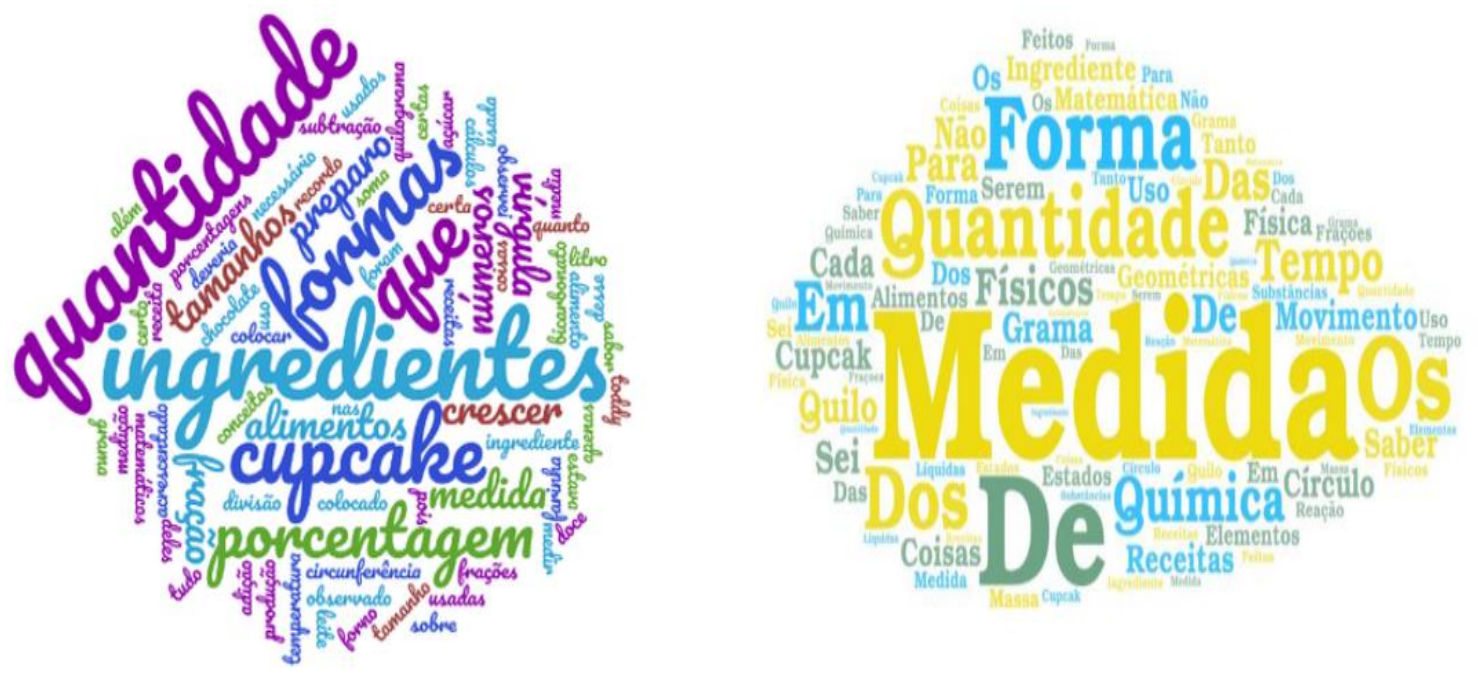

Fonte: Arquivo próprio

Inicialmente os alunos encontraram dificuldades para relacionar ciência à preparação do cupcake. Entretanto, a partir de uma prática dialogada, começaram a fazer conexões e a citar várias situações do cotidiano em que a ciência está presente, conseguindo relacionar a receita, o seu preparo e os conceitos científicos.

Em seguida aos questionários, desenvolveu-se a aula teórica com um diálogo sobre o projeto e os conceitos envolvidos (Figura 6). Várias perguntas foram esclarecidas, sempre relacionando os conteúdos com situações presentes no dia a dia, conquistando ainda mais o interesse das turmas. 
Figura 6. Alunos do Ensino Médio durante a aula teórica do cupcake.
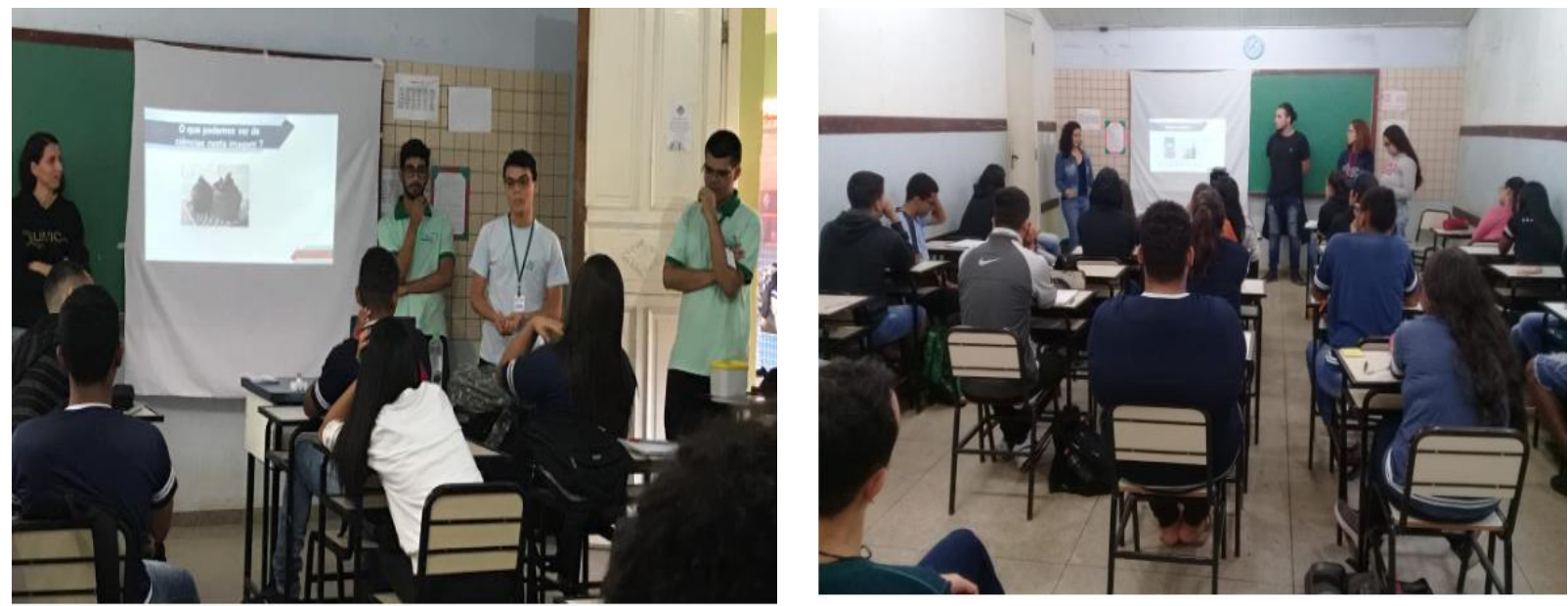

Fonte: Arquivo próprio

O segundo questionário está diretamente ligado à experiência que os alunos vivenciaram. Desse modo, observamos que houve progresso dos alunos em relação à compreensão dos conceitos trabalhados. Além disso, os dados foram tratados qualitativamente quanto ao conhecimento abordado e à construção do saber pelos discentes a respeito dos termos científicos. Por fim, estes resultados foram expressos por meio de nuvens de palavras, em que se observou a apropriação gradual dos conceitos trabalhados (Figura 7). Nesta segunda aplicação, os alunos apresentaram uma maior facilidade em responder às questões propostas e mostraram-se satisfeitos com o projeto, expressando vontade em continuar participando, o que contagiou professores, coordenadores, pibidianos e toda equipe da escola.

Figura 7. Nuvens de palavras referentes aos questionários realizados após a realização do experimento cupcake.
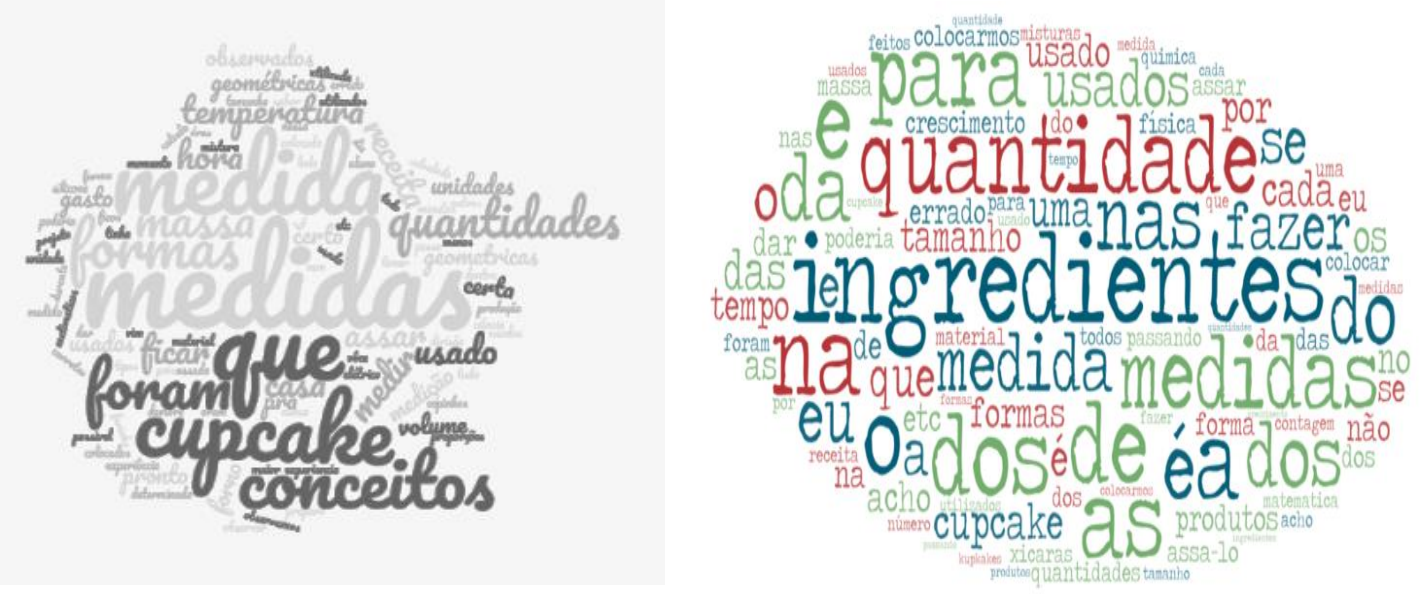

Fonte: Arquivo próprio 
Por fim, a satisfação dos alunos com essa experiência pedagógica foi avaliada e os dados foram tratados de forma quantitativa. Pôde-se observar, também, um sentimento de agrado e alegria dos que participaram desse momento, pois o projeto foi algo além da tradicional aula expositiva (Figura 8). Outrossim, os dados coletados foram utilizados como forma de aprimorar a segunda etapa do projeto Ciências com Sabor.

Figura 8. Gráfico de uma turma sobre a satisfação (em \%) com o projeto.

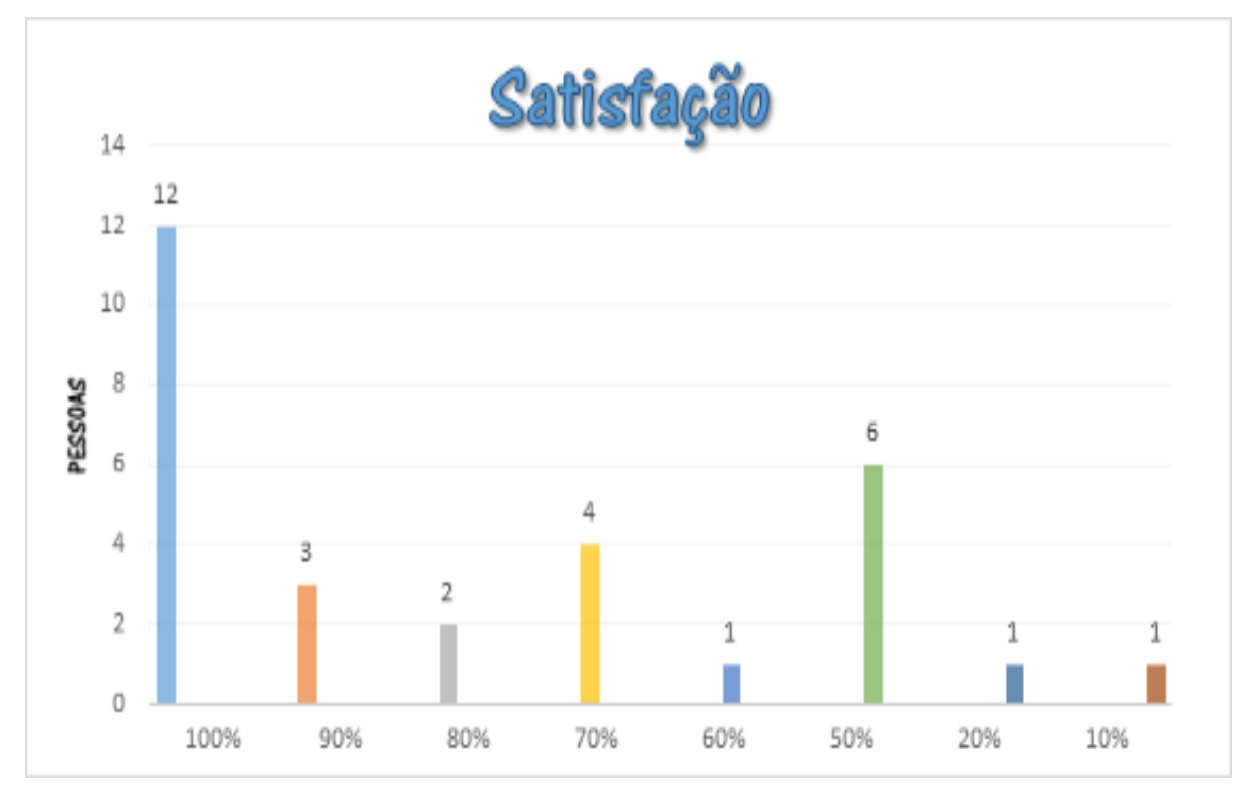

Fonte: Arquivo próprio

ETAPA 2: Gelatina

Neste momento, a prática antecedeu o tratamento teórico dos conteúdos trabalhados. Desta forma, os discentes puderam não só serem os protagonistas da prática, como também da própria aprendizagem (Figura 9). As equipes, em suas bancadas, seguiram o roteiro experimental e responderam às questões propostas. 
Figura 9. Preparação da gelatina pelos alunos.
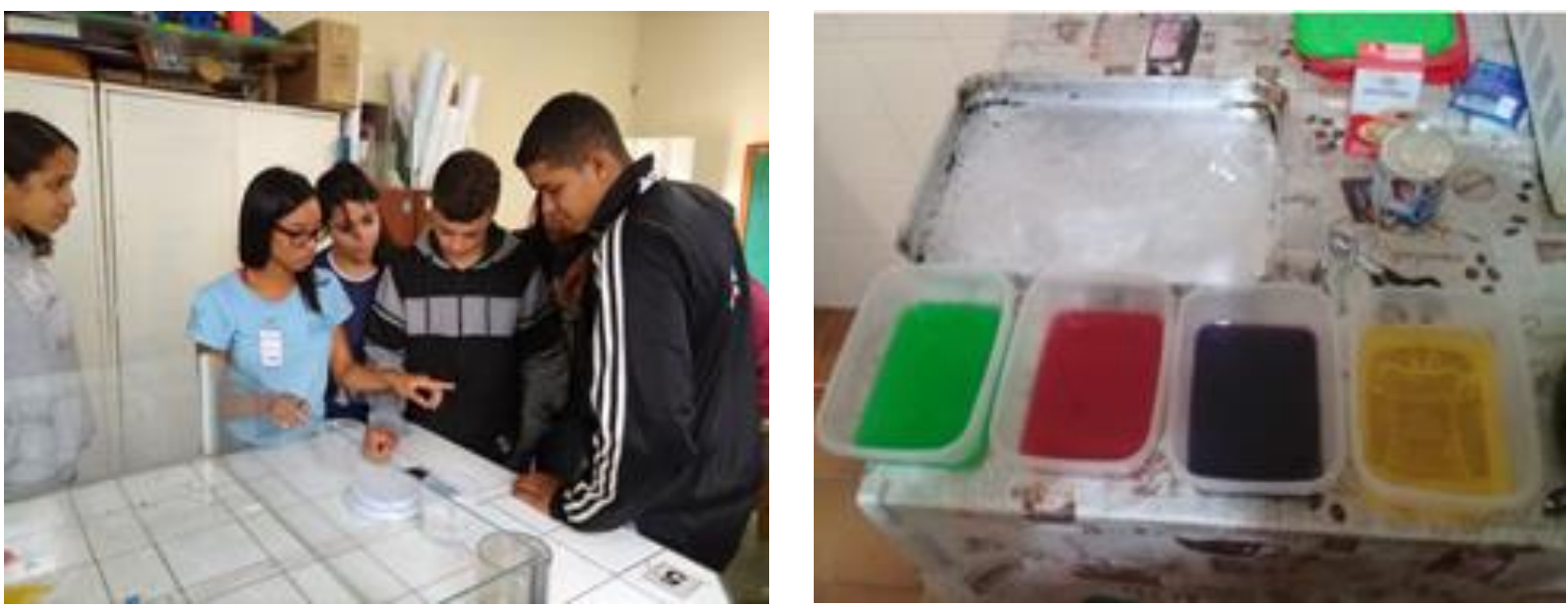

Fonte: Arquivo próprio

Pode-se observar que, com a nova estruturação do projeto, os discentes estavam mais engajados, estabelecendo relações entre o conteúdo e a prática no experimento. A partir das indagações a respeito do fenômeno científico que era observado, foi possível perceber a compreensão dos alunos, o que aponta para a consecução dos objetivos do projeto, pois já nesta fase os alunos mostravam a apuração do seu olhar científico sobre os fenômenos.

Figura 10. Respostas de alguns alunos ao questionário da etapa gelatina.

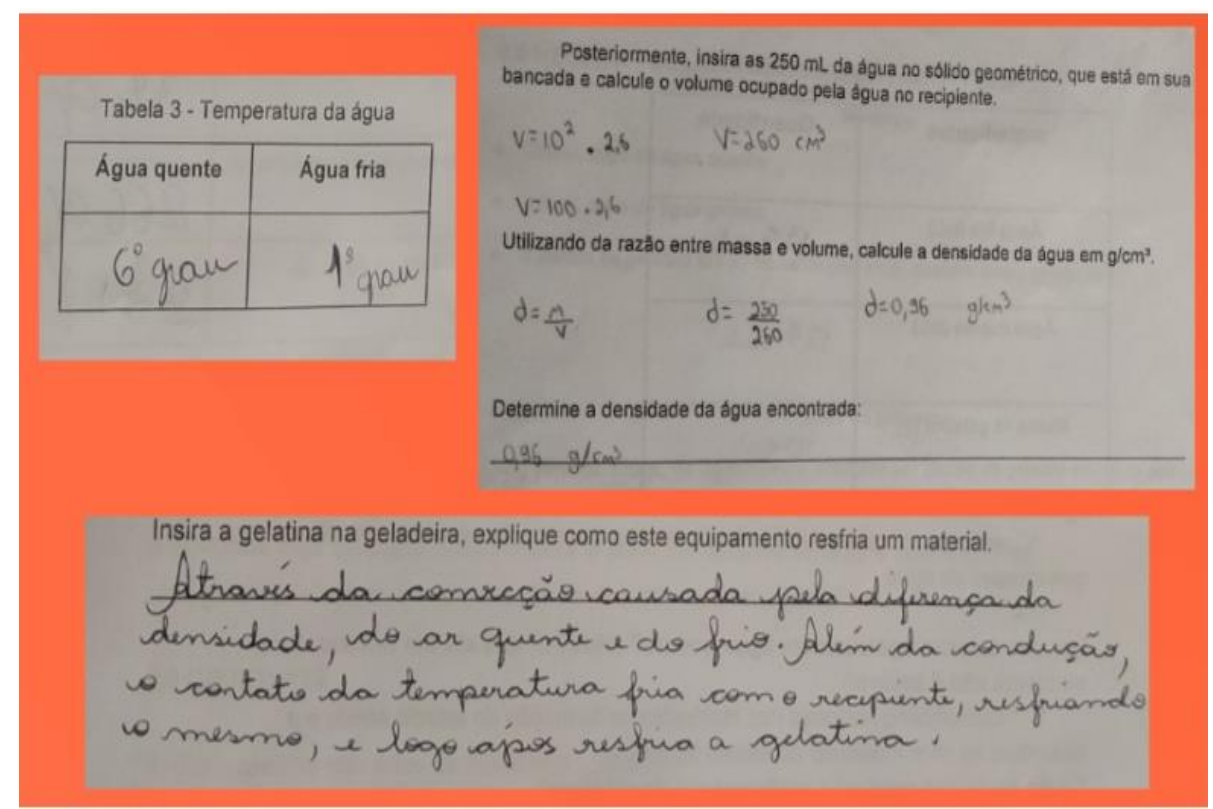

Fonte: Arquivo próprio

Num segundo momento, os dados dos alunos foram coletados para verificar o que eles estavam conseguindo entender, explicar e aplicar sobre os conceitos científicos presentes na 
atividade. Além disso, estabeleceram relações entre os conteúdos abordados na escola e acontecimentos do seu dia a dia.

Em seguida, a parte teórica foi lecionada e, juntamente com os alunos, os conceitos vistos na parte prática foram retomados com intuito de consolidar o que foi abordado (Figura 11). Este trabalho teve colaboração de grande parte dos alunos, tendo em vista que muitos sabiam os procedimentos e entendiam os fenômenos químicos, físicos e matemáticos. Ao fim, conclui-se que a aprendizagem foi significativa.

Figura 11. Aulas teóricas após a realização da aula prática da gelatina.
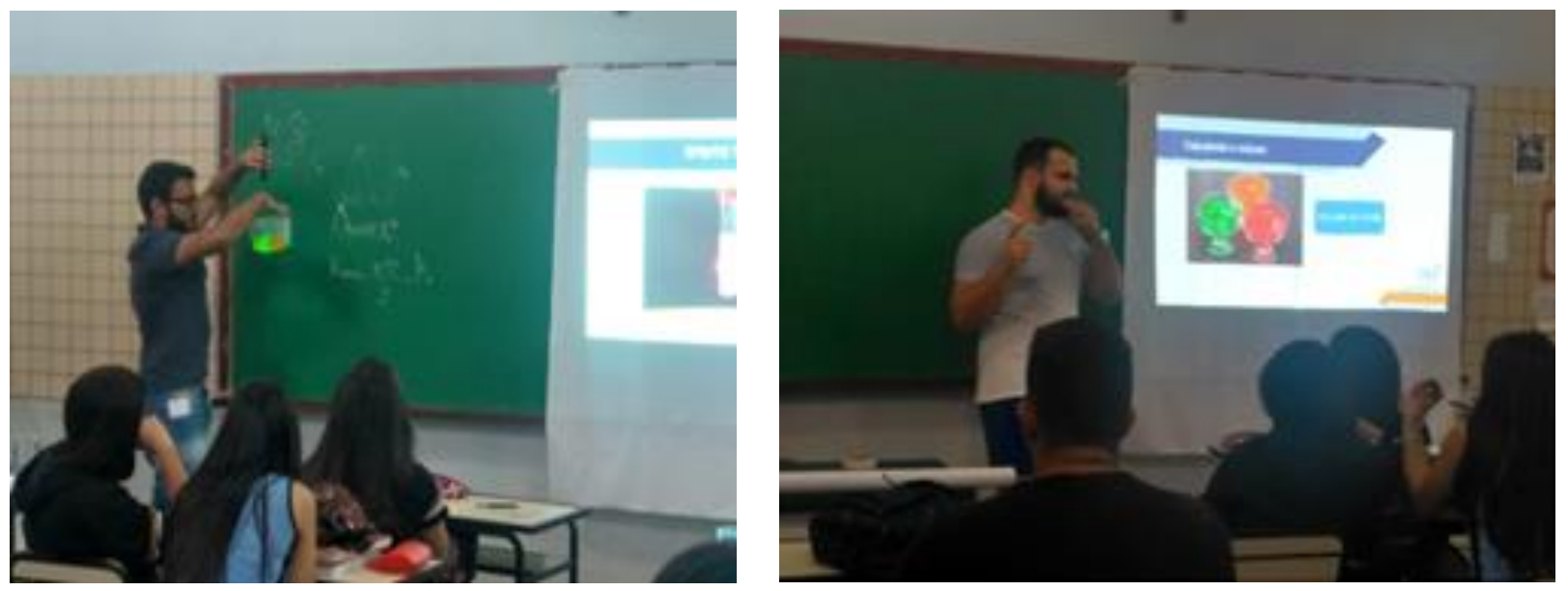

Fonte: Arquivo próprio

\section{CONSIDERAÇÕES FINAIS}

Diante das observações e vivências realizadas durante o projeto Ciências com Sabor, constatamos que a criatividade e o engajamento por parte de professores e pibidianos foram de suma importância para a construção de uma experiência de aprendizagem efetiva de caráter inovador e interdisciplinar. Lidar com os desafios do ensino público brasileiro e desinteresse de grande parte dos estudantes pelo aprendizado das ciências requer reavaliações, discussões e reformulações das práticas docentes que contribuam para a melhoria dos resultados educacionais apresentados atualmente no Brasil. Desta maneira, as práticas de ensino realizadas por este núcleo buscaram, desde o princípio, experimentar propostas inovadoras para o ensino de ciências, com o objetivo de desenvolver o letramento científico dos participantes.

A utilização de materiais visuais, jogos, dinâmicas, experimentos laboratoriais e diversos outros recursos didáticos tornaram a atuação do PIBID na Escola Doutor Mariano da Rocha uma 
experiência diferente, moderna, inovadora e agradável, tanto para os alunos da escola, quanto para os professores envolvidos e os pibidianos.

O projeto Ciências com Sabor alcançou seus objetivos ao propor práticas de ensino que propiciaram aos alunos experimentar, ver e pensar o conhecimento de uma forma complexa, integral e dinâmica. Pôde-se constatar que a interdisciplinaridade é uma alternativa eficaz para um aprendizado integrado e crítico, que dialoga com a experiência cotidiana dos estudantes. Além disso, desenvolve a capacidade de trabalho em grupo tanto pelos pibidianos quanto por parte dos alunos que participaram do projeto.

Neste contexto, a realização do projeto Ciências com Sabor, com seu caráter interdisciplinar e inovador, mostrou-se eficiente para o desenvolvimento do pensamento científico dos alunos. No decorrer das aulas experimentais, o entusiasmo dos estudantes foi perceptível, uma vez que a metodologia ativa utilizada no projeto é diferente das aulas tradicionais a que estão acostumados. Vale salientar que o caráter interdisciplinar do projeto possibilitou a melhor compreensão dos conteúdos das três disciplinas promovendo uma percepção da complexidade dos fenômenos.

O trabalho em conjunto dos pibidianos das diferentes disciplinas em prol de um objetivo comum tornou o aprendizado dos alunos mais efetivo, sublinhando a interdisciplinaridade e proporcionando uma visão mais ampla sobre como Física, Química e Matemática estão diretamente correlacionadas e presentes em nosso dia a dia.

Cabe destacar aqui alguns depoimentos de participantes do projeto:

- Um projeto muito interessante que eles desenvolveram aqui na escola foi o Ciências com Sabor ... porque a gente viu a teoria dialogando com a prática... eles usaram uma simples receita de um bolinho de chocolate, que é da vivência de nossos alunos, e os alunos puderam dali aprender vários conceitos... foi um momento muito alegre e... assim... os meninos ficavam muito felizes porque eles entendiam o conteúdo e ainda comiam um bolinho e... isso trouxe prá nossa escola um novo olhar... e ficou assim muito claro que o que aprendemos na escola é aplicado no nosso dia a dia. (Vice-diretora da Escola Dr. Mariano da Rocha)

- A gente participou junto do projeto Ciências com Sabor e foi uma experiência incrível aqui na escola... Foi muito incrível porque a gente aprende bem mais na prática do que na teoria. (Aluna A)

- A gente teve oportunidade de vivenciar na prática, fora da sala, a gente usou o espaço do Laboratório, prá gente foi muito interessante. (Aluno B)

-Fizemos duas receitas que a gente pôde comer depois que foi uma parte maravilhosa também... quando a gente foi fazer os cupcakes, a gente aprendeu porque o bolo sobe, porque a gente usa bicarbonato, vinagre, várias coisas na receita... a parte da gelatina, a gente aprendeu muito sobre medidas também... (Aluna $C$ )

Assim sendo, concluímos que práticas inovadoras para o ensino das ciências devem ser cada vez mais experimentadas a fim de tornar o aprendizado mais efetivo e interessante para os alunos como foi a experiência do Ciências com Sabor. 


\section{REFERÊNCIAS}

CACHAPUZ, A., GIL-PEREZ, D., CARVALHO, A. M. P., PRAIA, J., VILCHES, A. A Necessária renovação do ensino das ciências. São Paulo, Brasil: Cortez, 2005.

FREIRE, P. Desafios da educação de adultos ante a nova reestruturação tecnológica. In: Pedagogia da Indignação: cartas pedagógicas e outros escritos. São Paulo: UNESP, 2003.

FREIRE, P. Pedagogia do oprimido. 50. ed. Rio de Janeiro: Paz e Terra, 2011.

LEONTIEV, A. N. O desenvolvimento do psiquismo. São Paulo, Brasil: Editora Moraes, 1978.

MOREIRA, M. D. D. Matemática XXI: Conexões surpreendentes. 2016. Tese (Doutorado em Ensino e Divulgação das Ciências) Universidade do Porto, Porto (Portugal), 2016.

MORIN, E. Introdução ao pensamento complexo. Tradução de Eliane Lisboa. Porto Alegre: Sulina, 2006.

THIOLLENT, M. Metodologia da Pesquisa-ação. São Paulo: Cortez, 2011.

MOREIRA, M. D. D. Matemática XXI: Conexões surpreendentes. Tese de Doutorado. Universidade do Porto, Portugal, 2016. 